Artigo original

Hegemonia - Revista Eletrônica de Relações Internacionais do Centro Universitário Unieuro

ISSN: $1809-1261$

UNIEURO, Brasília, número 18, 2016, pp. 260-296.

Recebido em: 22/4/2016

Avaliado em: 17/5/2016

Aprovado em: 19/6/2016

\title{
Direitos Humanos e Saúde no Brasil: a contribuição das organizações sociais de saúde na gestão hospitalar
}

Iasmine Lorena Silva de Jesus ${ }^{1}$, Carla Pintas Marques ${ }^{2}$ e Aldira Guimarães Duarte Dominguez ${ }^{3}$

RESUMO: As organizações sociais de saúde (OSS) na gestão de unidades hospitalares surgem no Brasil a partir de uma necessidade de reorganização da administração pública burocrática e insuficiente para atender a demanda de unidades hospitalares, inicialmente no estado de São Paulo e em seguida em outros estados da Federação. O intuito deste trabalho é compreender e identificar de que forma as parcerias entre os setores público e privado tem ocorrido em três diferentes hospitais com modalidade de gestão por organização social de saúde. A pesquisa caracteriza um trabalho qualitativo, realizado a partir de entrevistas abertas junto a três gestores de unidades hospitalares distintas geridas por diferentes organizações sociais de saúde localizadas nos estados de São Paulo, Pernambuco e no Distrito Federal. Para que fosse possível compreender 0 funcionamento da gestão hospitalar por OSS alguns aspectos foram considerados relevantes dentre eles o modo como os estados adotaram o modelo de gestão por OSS e como estabelecem os contratos de gestão, as principais facilidades e dificuldades desse modelo. Os gestores entrevistados ainda fizeram considerações sobre a legislação, a fiscalização e o relacionamento das unidades hospitalares com os órgãos de governo de cada estado. As dificuldades e limitações na contratação ou aquisição de recursos

1 Especialista em Gestão de Redes de Atenção à Saúde e Bacharel em Saúde Coletiva.

2 Doutoranda em Ciências da Saúde e Docente da Universidade de Brasília.

3 Doutora em Saúde Coletiva e Docente da Universidade de Brasília. 
Artigo original

Hegemonia - Revista Eletrônica de Relações Internacionais do Centro Universitário Unieuro

ISSN: 1809-1261

UNIEURO, Brasília, número 18, 2016, pp. 260-296.

indispensáveis, sendo humanos, físicos ou materiais, trazem ao gerenciamento de unidades de saúde de administração direta complicações e dificuldades expressivas capazes de impedir o funcionamento e o gerenciamento adequados com os padrões de qualidade desejados. A procura por parcerias entre os setores público e privado, através das organizações sociais de saúde, delega ao setor privado a administração dos recursos públicos em unidades de demanda e atendimento do próprio Sistema Único de Saúde, sem prejuízo a população e com garantia de cumprimento dos contratos estabelecidos. As experiências encontradas neste trabalho são destaque de importante processo de alternativas à gestão pública e da importância de se registrar as experiências dos serviços.

Palavras chave: organizações sociais; gestão hospitalar; saúde coletiva; saúde pública.

Introdução

A administração pública direta no Brasil apresenta muitas dificuldades que são consequências de seus aspectos históricos, sociais e políticos. Dentre os principais desafios é válido ressaltar a instauração de um sistema burocrático, muitas vezes corrupto e descontínuo administrativamente, o que torna os processos de tomada de decisão e de contratação de pessoas, obras e serviços lentos e ineficientes, gerando assim uma gestão pública falha e por vezes incapaz de realizar aquilo a que se propõe.

A insuficiência de recursos é uma justificativa bastante utilizada pelos gestores públicos para findar questionamentos sobre as falhas ocorridas nos serviços. Entretanto após a criação da Norma Operacional Básica do Sistema Único de Saúde (SUS) em 1996 (BRASIL, 1996) o setor saúde passa a ter seus recursos transferidos fundo a fundo, ou seja, de modo regular e automático, e a ausência de recursos passa a não justificar distorções continuadas sobre a prestação de serviços. Porém o mau gerenciamento desses recursos 
Artigo original

Hegemonia - Revista Eletrônica de Relações Internacionais do Centro Universitário Unieuro

ISSN: $1809-1261$

UNIEURO, Brasília, número 18, 2016, pp. 260-296.

pode ocasionar danos e prejuízos ao sistema, sendo o principal fator de críticas ao SUS.

Como uma das alternativas propostas no processo de reforma do Estado, surgem as Organizações Sociais (OS), que são organizações privadas sem fins lucrativos que são contratadas pelos poderes públicos para executar atividades públicas por uma dada forma de contratação (ANDRADE, 2011), que garante a prestação de serviços, por parte da OS, e o repasse financeiro, por parte do órgão público contratante. As OS podem atuar com o aval de uma legislação específica que seja adequada ao segmento gerenciado.

Este modelo de OS foi replicado para o setor saúde pelas Organizações Sociais de Saúde (OSS). A possibilidade de uma gestão de serviços por OSS permite que a saúde possa sanar dificuldades encontradas na administração pública como, por exemplo, a obrigatoriedade de contratação de pessoal por regime celetista, a possibilidade de aquisição de bens, obras e serviços por outros meios que não a licitação, meios esses que podem vislumbrar também qualidade técnica comprovada e não somente menor preço.

As OSS têm suas parcerias com as Secretarias Estaduais de Saúde (SES) celebradas por meios de contratos de gestão que dispõem das formas de compras e contratação, tratam de legislação particular e firmam principalmente o estabelecimento de metas quantitativas e qualitativas que devem ser alcançadas para que 0 recurso repassado pela SES seja garantido em sua totalidade. O não cumprimento total das metas está sujeito às penalizações financeiras para a instituição, sendo essa uma forma de obrigatoriedade para a prestação adequada de serviço (BRASIL, 2011).

No Brasil os primeiros exemplos de gestão de unidades de saúde surgem no estado de São Paulo em diversos hospitais com características diferenciadas. O modelo também já é adotado em 
Artigo original

Hegemonia - Revista Eletrônica de Relações Internacionais do Centro Universitário Unieuro

ISSN: $1809-1261$

UNIEURO, Brasília, número 18, 2016, pp. 260-296.

diversos outros estados, como Pernambuco na gestão de unidade hospitalar e também no gerenciamento de Unidades de Pronto Atendimento (UPAs), e no próprio Distrito Federal em um hospital de pediatria especializada.

Considerado ainda um modelo de gerenciamento de serviço público inovador, as OSS passam a ser observadas, e os seus pontos positivos e negativos apontados seja para as críticas ao modelo proposto, seja para a implantação do mesmo modelo em locais onde a gestão pública é falha e pouco resolutiva. Faz-se necessário conhecer os ganhos e as limitações advindas da gestão hospitalar por oss.

A qualificação de OSS para a gestão de unidades hospitalares precisa ser vista de modo completo, e para isso é preciso identificar o modo como tem se dado as experiências existentes em diferentes regiões do Brasil, cada experiência com sua particularidade de nível de atenção e especialização de cuidado, visto que só após essa análise será possível entender de que modo a curto e/ou longo prazo essas organizações se desenvolveram no país.

Diante da realidade de novas modalidades de gestão hospitalar, esse trabalho se propõe a compreender como tem sido a experiência de gestão de unidades de saúde por OSS em três unidades hospitalares do Brasil, para verificar os resultados desse gerenciamento, identificando os reflexos da gestão por OSS no atendimento prestado à população e ainda verificando os interesses das secretarias de saúde em manter hospitais gerenciados por esse tipo de modalidade.

O desenvolvimento das Organizações Sociais de Saúde no Brasil

A crise do Estado brasileiro acontece com evidência em meados dos anos 1980, que acontece e meio a tentativa de superação das grandes intervenções econômicas e sociais do Estado, que 
Artigo original

Hegemonia - Revista Eletrônica de Relações Internacionais do Centro Universitário Unieuro

ISSN: $1809-1261$

UNIEURO, Brasília, número 18, 2016, pp. 260-296.

caracterizava uma forte burocracia e certa rigidez nos processos, em serviços centralizados em poder estatal.

Com a proposta de sanar os efeitos provocados pela crise nacional surge, nos anos 1990, uma alternativa de colocar o Estado em processo de reforma, objetivando construir políticas públicas junto à sociedade, e adotando controle financeiro autônomo (BRASIL, 1997).

Como elemento dessa reformulação do Estado surge o Plano Diretor da Reforma do Aparelho do Estado (PDRAE) em 1995 que orienta o movimento de reforma e surge com o objetivo de tornar a administração pública mais eficiente e voltada para a cidadania, redefinindo o papel do Estado, que até o plano tinha responsabilidade direta de produzir bens e serviços, e com a reforma passa a exercer a função de promover e regular o desenvolvimento de prestação de bens e serviços.

De acordo com o Plano Diretor da Reforma do Aparelho do Estado (1995), as organizações sociais são entidades de interesse e de utilidade pública, associações sem fins lucrativos, surgidas da qualificação de pessoas jurídicas de direito privado, nas atividades de ensino, pesquisa tecnológica, desenvolvimento tecnológico, proteção e preservação do meio-ambiente, cultura e saúde.

O modelo de organização social acontece através de uma entidade pública não pertencente ao estado, de um modo geral associações civis sem fins lucrativos, que se destina a absorver e realizar atividades orientadas ao atendimento de interesses públicos (BRASIL, 1998).

Esse modelo surge carregado de pressupostos que buscam trazer a prestação de serviços públicos maior qualidade com menor utilização de recursos, focando os resultados diretos e para isso facilitando os processos da rotina administrativa. 


\section{Artigo original}

Hegemonia - Revista Eletrônica de Relações Internacionais do Centro Universitário Unieuro

ISSN: $1809-1261$

UNIEURO, Brasília, número 18, 2016, pp. 260-296.

Em 1998, foi possível estabelecer o início das instituições que adotariam papéis de organizações sociais, pela Lei Federal no 9.637, que dispõe sobre a qualificação de entidades como organizações sociais, estabelecendo normas e providências sobre os conselhos administrativos; os contratos de gestão em sua elaboração, execução e fiscalização; as desqualificações; entre outras medidas.

Além da normatização da União, há para cada um dos Estados envolvidos nesse estudo legislação própria a tratar da qualificação de OS. O estado de São Paulo, pioneiro no segmento, dispõe sobre a qualificação das organizações sociais com a Lei complementar $n^{0}$ 846, de 1998.

Como suporte legislativo, o Distrito Federal criou a Lei Distrital no 2.415, de 6 de julho de 1999 para dispor sobre a qualificação de entidades como OS no âmbito do Distrito Federal, e ainda a Lei $\mathrm{n}^{0}$ 2.523, de 13 de janeiro de 2000 que altera a Lei no 2.415, de 6 de julho de 1999.

O estado de Pernambuco possui a Lei no 11.743 de 20 de janeiro de 2000, que sistematiza a prestação de serviços públicos não exclusivos, que dispõe sobre a qualificação de Organizações Sociais e Organizações da Sociedade Civil de Interesse Público e o fomento às atividades sociais, e dá outras providências.

Outros estados brasileiros também adotaram o modelo de OSS, e assim como os três, supracitados, possuem sua legislação própria a dispor sobre o assunto.

O papel das Organizações Sociais de Saúde 
Artigo original

Hegemonia - Revista Eletrônica de Relações Internacionais do Centro Universitário Unieuro

ISSN: $1809-1261$

UNIEURO, Brasília, número 18, 2016, pp. 260-296.

As organizações sociais na gestão pública possibilitam mudanças nas diferentes dimensões da administração pública, por atuar de modo diferenciado no que diz respeito à estrutura dos processos gerenciais; à organização dos processos de compra; à gestão dos recursos humanos, em formas de contratação e remuneração; entre outros.

A conexão estabelecida entre o órgão administrativo de saúde do ente federado e as organizações sociais são os denominados contratos de gestão que segundo Andrade (2011, p. 593) "configuram acordos administrativos colaborativos (ou contratos de gestão externos ou exógenos), os quais envolvem, de um lado, órgãos ou entidades administrativas, e de outro, entidades privadas sem fins lucrativos".

Os contratos de gestão são responsáveis pelo estabelecimento de vínculo entre a entidade administrativa e a organização social, visto que nesse instrumento contratual são contratadas e pactuadas as metas e obrigações que afirmam a colaboração e responsabilização de ambos sobre a unidade a ser gerenciada, visando o controle de comportamento que indicará os resultados atingidos previamente acordados (IBANEZ, VECINA NETO, 2007).

O estabelecimento desse contrato, quando pactuado em negociação harmoniosa entre a secretaria de saúde e a instituição prestadora do serviço possibilita o aprimoramento das metas estabelecidas, assim como um maior controle e mais qualidade na avaliação da prestação dos serviços. A relação do aparelho do estado com as entidades qualificadas como OSS precisa ser bem estabelecida de modo a delimitar as responsabilidades de cada uma das partes contratantes, assim se torna possível aplicar ao setor saúde políticas que aumentarão a eficiência do serviço prestado. 
Artigo original

Hegemonia - Revista Eletrônica de Relações Internacionais do Centro Universitário Unieuro

ISSN: $1809-1261$

UNIEURO, Brasília, número 18, 2016, pp. 260-296.

A transparência na gestão dos recursos públicos dificulta a repetição de erros já conhecidos na administração direta, e ainda possibilita mais abertura ao controle social que pode, também, utilizar dos indicadores quantitativos e qualitativos estabelecidos no contrato de metas para realizar comparativos e identificar ganhos e perdas por essa modalidade de gestão.

A saber, somente a partir do cumprimento de metas quantitativas e qualitativas estabelecidas no documento contratual é possível manter o repasse financeiro do órgão de governo à unidade hospitalar. Fato que "obriga" as instituições gerenciadas por organizações sociais a manterem linearidade na prestação de serviços que se propõem.

A gestão por Organizações Sociais de Saúde

Considerando as atuais falhas que cercam a administração pública do SUS, a presença de diversas OSS presentes e atuantes no Brasil, e ainda o contexto no qual se deu o surgimento dessa modalidade de gestão no país, várias razões são apresentadas para a aprovação ou reprovação desse modelo.

Costa, Junior e Nascimento (2011) ressaltam que também a permanente tensão devido aos recursos limitados e as dificuldades gerenciais do setor público para atingir metas assistenciais e conferir eficácia e eficiência de ação, exigências encontradas no cotidiano da iniciativa privada. Para ele essa tensão se expressa com muita ênfase no setor saúde, já que envolve a necessária agilidade na aquisição de inovações tecnológicas, incremento constante na oferta de procedimentos médicos, exames e insumos, diversificação e especialização das práticas, instalações modernas e acolhedoras. De modo que essas razões também justificam a aproximação dos 
Artigo original

Hegemonia - Revista Eletrônica de Relações Internacionais do Centro Universitário Unieuro

ISSN: 1809-1261

UNIEURO, Brasília, número 18, 2016, pp. 260-296.

governos locais junto às instituições privadas sem fins lucrativos, como meio de otimizar os recursos de acordo com as necessidades.

Segundo documento do Ministério da Administração Federal e Reforma do Estado, as OS tornam mais fácil e direto o controle social, por meio da participação nos conselhos de administração dos diversos segmentos representativos da sociedade civil, ao mesmo tempo em que favorece seu financiamento via compra de serviços e doações por parte da sociedade. Ressalte-se ainda que gozam de uma autonomia administrativa muito maior do que aquela possível dentro do aparelho do Estado e em compensação, seus dirigentes são chamados a assumir uma responsabilidade maior, em conjunto com a sociedade, na gestão da instituição e na melhoria da eficiência e da qualidade dos serviços, atendendo melhor o cidadão-cliente a um custo menor (BRASIL, 1997).

Abrucio e Sano (2008) enfatizam os pontos fortes trazidos por essa modalidade de gestão de modo incisivo e evidenciam ainda que as falhas da administração pública direta é fator determinante para que isso ocorra. Segundo esses autores a explicação desse sucesso das OS têm a ver, basicamente, com três fatores. Primeiro, com a flexibilização administrativa, que favorece um melhor gerenciamento. Segundo, com o mecanismo do contrato de gestão, que aumenta a capacidade de planejar e executar por meio de metas capazes de serem avaliadas. Por fim, com o êxito do modelo de repasse a entes públicos não estatais, que só deu certo em São Paulo, porque foi constituído um núcleo burocrático estratégico na Secretaria de Estado da Saúde, capaz de regular, monitorar, avaliar e, eventualmente, alterar o rumo do processo de contratualização.

Abrucio e Sano (2008) ainda ressaltam que esses três aspectos também aparecem nas experiências bem-sucedidas de outros países no campo da gestão por resultados. O sucesso gerencial obtido nas 
Artigo original

Hegemonia - Revista Eletrônica de Relações Internacionais do Centro Universitário Unieuro

ISSN: $1809-1261$

UNIEURO, Brasília, número 18, 2016, pp. 260-296.

OS paulistas deixam mais claro os problemas do modelo administrativo público brasileiro.

É de extrema importância que se compreenda de que modo o desenvolvimento dessa modalidade de gestão vem se apresentando no país para que entre opiniões favoráveis e desfavoráveis fique claro se $o$ atendimento prestado por essas unidades de saúde tem sido efetivo em sua essência, ou seja, se são cumpridos os princípios e diretrizes estabelecidos pelo SUS.

Ressalto que, mesmo em meio à polêmica e a disparidade de opiniões acerca das organizações sociais há pouca literatura que relate ou avalie as experiências nacionais. De um modo geral, o estado de São Paulo apresenta destaque em vivência e literatura, porém nos demais estados pouco se relata, apesar de as organizações sociais de saúde já estarem presentes em muitos deles. Relato de experiências em gestão hospitalar em três estados brasileiros

O presente estudo foi realizado a partir de entrevistas abertas junto a três gestores de unidades hospitalares distintas geridas por diferentes organizações sociais de saúde localizadas nos estados de São Paulo, Pernambuco e no Distrito Federal.

A escolha das três unidades federadas se deu, pois esses estados possuem organizações sociais gerenciando unidades de saúde, possuem ainda legislação própria que trata sobre o funcionamento das organizações sociais, bem como, sobre os seus processos internos e externos.

Foi elaborado um roteiro orientador para nortear as entrevistas com os gestores das unidades hospitalares gerenciadas pela OSS e estabelecidas questões relativas ao cumprimento dos contratos de metas, dificuldades e facilidades, relações institucionais entre a unidade gestora com as secretarias estaduais e municipais. O roteiro 


\section{Artigo original}

Hegemonia - Revista Eletrônica de Relações Internacionais do Centro Universitário Unieuro

ISSN: $1809-1261$

UNIEURO, Brasília, número 18, 2016, pp. 260-296.

serviu como base para o andamento das entrevistas, que foram realizadas em datas agendadas com os gestores, gravadas e transcritas, no período de 01 a 20 de fevereiro de 2013. Em duas instituições o encontro se deu de modo presencial, acompanhado de visita a unidade de saúde correspondente e na terceira instituição foi realizada vídeo conferência, por incompatibilidade de datas para entrevista in loco.

As instituições não serão identificadas e serão tratadas aqui como IA, IB e IC. Os gestores entrevistados também não serão identificados, e serão chamados GA, GB e GC sendo correspondentes às suas instituições.

Para que fosse possível compreender o funcionamento da gestão hospitalar por organizações sociais de saúde alguns aspectos foram considerados relevantes, e, por isso, adotados como tema de questionamentos levantados durante as entrevistas realizadas com gestores das instituições propostas.

Para procedermos à análise, utilizaremos a sequência de itens de maior relevância, propostos pelo roteiro elaborado, com uma síntese final de cada item avaliado.

Item 1. A adoção ao modelo de OSS

A Instituição A (IA) apresenta-se de modo particular no que se refere ao vínculo estabelecido entre o governo estadual e a sociedade civil como retratado pelo Gestor A (GA): "O hospital tem um processo longo de maturação do seu desenvolvimento, ele surge de uma 
Artigo original

Hegemonia - Revista Eletrônica de Relações Internacionais do Centro Universitário Unieuro

ISSN: $1809-1261$

UNIEURO, Brasília, número 18, 2016, pp. 260-296.

iniciativa da sociedade civil com a construção do primeiro bloco do hospital, depois se buscou uma maneira de operacionalizar, uma vez que seu funcionamento requereria recursos regulares e significativos. Foram feitos entendimentos com o governo local, que culminaram com a doação da estrutura física ao governo, e o governo optou por colocar uma organização social para gerir o hospital. O que a nível local representa uma experiência nova. As forças políticas aqui estão alinhadas com a motivação de outros estados mais experientes nesse tipo de modelo, exatamente pela dificuldade, quase impossibilidade, de uma gestão direta, há um emaranhado jurídico enorme, e na área da saúde particularmente difícil, dadas as características do setor que é muito dinâmico e requer decisões muito rápidas. Tentativa de buscar modelo alternativo, para agilizar e dar eficiência e eficácia à gestão".

A Instituição B (IB) foi construída para ser gerenciada por uma OSS, sendo que a mesma não teve participação na construção física da unidade hospitalar. Seu Gestor B (GB) relata essa situação: "O Estado tinha todo interesse que $O$ hospital iniciasse 0 seu funcionamento imediatamente, e entregou o hospital à OSS todo montado, todo equipado. À OSS coube fazer a seleção de pessoal, e entrar gerenciando o hospital".

A Instituição C (IC) passa por um processo mais longo até se tornar um hospital gerenciado por OSS, como conta o Gestor C (GC): "O hospital foi criado para ser uma unidade Federal e nos anos 1970 foi cedido ao governo do estado, com o sucateamento da unidade, que ocorreu ao longo dos anos, em 2004 uma ação do Ministério Público deu como alternativas ao estado a demolição da unidade ou a reforma completa. A partir daí o hospital foi reformado, com investimento do estado, após a reforma a SES modificou o perfil do hospital. Sendo assim, o estado lançou edital público para adoção da 
Artigo original

Hegemonia - Revista Eletrônica de Relações Internacionais do Centro Universitário Unieuro

ISSN: $1809-1261$

UNIEURO, Brasília, número 18, 2016, pp. 260-296.

gestão por OSS, o projeto mais adequado ao interesse estatal foi selecionado, e assume a gestão até hoje".

Quadro 1. Quadro Síntese sobre a adoção do Modelo de OSS. Brasília, 2013.

\begin{tabular}{|c|c|c|}
\hline \multicolumn{3}{|c|}{ ADOÇÃO DO MODELO DE OSS } \\
\hline \multicolumn{3}{|c|}{ Instituição / Gestor } \\
\hline A & B & C \\
\hline Iniciativa da sociedade & Interesse de início & Hospital Federal \\
Necessidade de & imediato; & cedido ao estado; \\
recursos regulares e & equipamentos a cargo & Sucateamento da \\
significativos; & do Estado; & unidade; \\
Busca de alternativa & Contratação de RH a & Redefinição do \\
ágil, eficiente e eficaz. & cargo da OSS. & perfil da unidade. \\
\hline
\end{tabular}

Fonte: Elaborado pelo autor.

Grande parte dos estados da federação tem-se utilizado da parceria junto às OSS como modalidade de gestão hospitalar, em especial por conta de dificuldades encontradas na administração pública direta. As unidades hospitalares têm processos de inicialização bem diferentes uns dos outros, porém nas três situações verificou-se que há interesse do Estado em agilizar e dar eficiência à prestação de serviços.

Item 2. Experiências dos gestores e comparações a modelos tradicionais

Os gestores das unidades hospitalares retratadas nessa pesquisa tiveram experiências em outras modalidades de gerenciamento, o que permitiu comparações e destaques para as 
Artigo original

Hegemonia - Revista Eletrônica de Relações Internacionais do Centro Universitário Unieuro

ISSN: $1809-1261$

UNIEURO, Brasília, número 18, 2016, pp. 260-296.

diferenças percebidas entre as modalidades de gestão tradicionais e a gestão por OSS.

GA conta que já foi "gestor de área técnica em unidade de gestão pública direta, e gestor em dois hospitais com modelo OSS em outro estado", ainda ressalta que "o modelo de gestão direta apresenta uma enorme dificuldade operacional" para ele "é reconhecido que a gestão pública é muito complicada, e por isso temse buscado mecanismos de minimizar essas dificuldades, associada a essa questão estritamente funcional de gestão há outros aspectos relacionados a essa situação que dizem respeito ao papel do estado na execução de suas funções".

GB relata que "Já havia gerenciado a área técnica de outra unidade hospitalar, porém na forma de administração direta", e aponta a maior diferença entre a gestão tradicional e o modelo OSS: "Considero como diferença fundamental entre os dois modelos o que diz respeito ao gerenciamento de pessoal".

Já o GC, relata que teve experiência em unidade hospitalar com administração direta e em outra unidade com modalidade de gestão por OSS. Sendo mais pontual ao relatar sua percepção das limitações que a administração direta pode ter: "Na administração direta existem muitas dificuldades porque trabalhamos com um funcionário que com o passar dos anos vai assumindo uma posição de quem já tem estabilidade, então ele faz mais ou menos o que quer, é um funcionário que se acomoda; Você não pode dizer que o funcionário público é ruim, até porque ele passa por uma seleção por concurso público, ele é bom, mas com essa forma gerencial as coisas demoram tanto, que as pessoas no começo tentam realizar mais, mas depois desanimam", para GC "a estrutura do poder público é lenta pra conseguirmos mudar as coisas, então dá a impressão que você está diante de uma montanha que se mexe, mas você não vê. Demora 
Artigo original

Hegemonia - Revista Eletrônica de Relações Internacionais do Centro Universitário Unieuro

ISSN: $1809-1261$

UNIEURO, Brasília, número 18, 2016, pp. 260-296.

muito tempo pra que as modificações sejam percebidas. Há uma situação de inércia por parte dos profissionais, motivar as pessoas para fazer as coisas exige um esforço muito grande, com pouco retorno".

Quadro 2. Quadro Síntese sobre experiências dos gestores e comparações a modelos tradicionais. Brasília, 2013.

\begin{tabular}{|c|c|c|}
\hline \multicolumn{3}{|c|}{$\begin{array}{l}\text { EXPERIÊNCIAS DOS GESTORES E COMPARAÇÕES A MODELOS } \\
\text { TRADICIONAIS }\end{array}$} \\
\hline & & \\
\hline$A$ & $B$ & C \\
\hline $\begin{array}{l}\text { Gestor de área técnica } \\
\text { em unidade de gestão } \\
\text { pública direta; } \\
\text { Gestor de modelo oss } \\
\text { em outro estado; } \\
\text { Gestão direta dificulta } \\
\text { operacionalização; } \\
\text { Necessidade de } \\
\text { minimizar dificuldades; } \\
\text { Novas alternativas; } \\
\text { Definição do papel do } \\
\text { estado na execução de } \\
\text { funções. }\end{array}$ & $\begin{array}{l}\text { Gestor de área } \\
\text { técnica em } \\
\text { unidade de gestão } \\
\text { pública direta; } \\
\text { Diferença } \\
\text { fundamental entre } \\
\text { modelos: } \\
\text { gerenciamento de } \\
\text { pessoal. }\end{array}$ & $\begin{array}{c}\text { Gestor de área } \\
\text { técnica em unidade } \\
\text { de gestão pública } \\
\text { direta; } \\
\text { Gestor de modelo } \\
\text { OSS no mesmo } \\
\text { estado; } \\
\text { Funcionários da } \\
\text { administração direta } \\
\text { bons, porém } \\
\text { acomodados com o } \\
\text { tempo; } \\
\text { Poder público lento } \\
\text { para mudanças. }\end{array}$ \\
\hline
\end{tabular}

Fonte: Elaborado pelo autor.

A carga de experiência em gestão dos três entrevistados permitiu o arcabouço comparativo ao modelo de administração direta tradicional. A percepção de lentidão, pouca eficiência e excessos 
Artigo original

Hegemonia - Revista Eletrônica de Relações Internacionais do Centro Universitário Unieuro

ISSN: $1809-1261$

UNIEURO, Brasília, número 18, 2016, pp. 260-296.

burocráticos em experiências anteriores, fizeram com que as

facilidades operacionais do modelo OSS fossem ressaltadas.

Ressaltadas as necessidades de revisão da administração direta, Santos (2010) reforça que a Administração Pública precisa inovar-se, pois a operacionalidade no caso dos serviços que devem assegurar o direito à saúde é insatisfatória e não garante a efetividade do direito à saúde. A autora ainda reforça a necessidade de promover uma reforma no seu interior, adotando-se novos marcos legais condizentes com as atuais necessidades da população em relação aos serviços públicos.

Item 3. Facilidades encontradas no modelo OSS

As facilidades do processo são percebidas por GA principalmente no que diz respeito aos processos de contratação e aquisição de serviços e bens, é pontual ao dizer que "a nossa vantagem é não estarmos obrigados a realizar processos de licitação típicos, o que fazemos é um processo de publicização. Os processos devem ser públicos, com prazos e regras, mas não chega aos rigores de um processo licitatório".

Para GB "A maior facilidade é a possibilidade de contratação e demissão direta de pessoal, montar equipe, principalmente a assistencial". Adianto aqui que nessa localidade a legislação não permite outras contratações, que não as de pessoal, por parte da oss.

GC acredita que "os processos são facilitados, porque você pode decidir, dentro do orçamento que the é fornecido de que modo você pode otimizar isso". Para esse gestor "montar equipe ficou muito mais fácil, porque você consegue requisitar bons profissionais, de modo ágil sem a necessidade de abertura de concurso público, além 
Artigo original

Hegemonia - Revista Eletrônica de Relações Internacionais do Centro Universitário Unieuro

ISSN: $1809-1261$

UNIEURO, Brasília, número 18, 2016, pp. 260-296.

disso, na modalidade OSS a agilidade é maior, a equipe se torna muito mais motivada".

Quadro 3. Quadro Síntese sobre facilidades encontradas no modelo OSS. Brasília, 2013.

\begin{tabular}{|c|c|c|}
\hline \multicolumn{3}{|c|}{ FACILIDADES ENCONTRADAS NO MODELO OSS } \\
\hline A & Instituição / Gestor \\
\hline Processo & Possibilidade de & C \\
licitatório não \\
obrigatório; \\
$\begin{array}{c}\text { Realização de } \\
\text { contratação e demissão } \\
\text { direta de pessoal; }\end{array}$ & $\begin{array}{c}\text { Decisão de otimizar } \\
\text { recursos; } \\
\text { Agilidade para montar } \\
\text { equipe mais motivada. }\end{array}$ \\
\hline
\end{tabular}

Fonte: Elaborado pelo autor.

A proposta do modelo OSS permite a facilitação dos processos envolvidos nos trabalhos dentro da organização, afinal esse modelo foca nos resultados que a instituição deve obter.

É importante ressaltar que as facilidades adquiridas com as legislações de OSS não significam perda de qualidade ou de seriedade na realização dos processos. Essas facilitações vêm acompanhadas de um controle estatal ainda não existente na administração direta, que é mais rigoroso e punitivo quando as necessidades não são atendidas.

Sobre as facilidades do modelo OSS, Barbosa e Elias (2010) reforçam que $O$ nível de autonomia administrativa e financeira concedido às OSS, tanto para aquisição de bens e serviços quanto para contratação de recursos humanos, permite que, dentro dos limites orçamentários estabelecidos, sejam feitos todos os arranjos institucionais que garantam o melhor uso possível dos recursos destinados. 
Artigo original

Hegemonia - Revista Eletrônica de Relações Internacionais do Centro Universitário Unieuro

ISSN: $1809-1261$

UNIEURO, Brasília, número 18, 2016, pp. 260-296.

Item 4. Dificuldades encontradas no modelo OSS

O modelo OSS traz em seus pressupostos a intenção de facilitar o manejo dos processos, sem perder o controle sobre eles. Entretanto cada estado possui particularidades em sua própria legislação, o que determina diferenças consideráveis que geram comparações entre as formas de aplicação desse modelo.

GA revela particularidades em sua localidade: "O modelo adotado aqui é muito diferente dos outros estados, o arcabouço jurídico é o mesmo, mas em outros locais as instituições realizam processos dentro das diretrizes e da lógica do setor privado. Aqui, pelas circunstâncias locais e falta de tradição, estamos submetidos a uma legislação muito restritiva, o que nos aproxima muito de uma administração pública tradicional, a necessidade de percorrer um trajeto legal de justificativas, recomendações e de atender os órgãos de controle transformam a nossa gestão em algo muito próximo da gestão pública".

GB passa por dificuldades particulares com relação aos outros Estados apresentados neste estudo, a legislação diferenciada atrela as dificuldades do processo à preocupação em longo prazo sobre os rumos que a unidade hospitalar irá tomar, a fala de GB esclarece esse ponto: "A maior dificuldade é não poder ter verba de investimento, o que impossibilita autonomia para execução de processos de compra e troca de materiais e equipamentos, e para a execução de obras. A OSS não tem autonomia nenhuma para execução de obras ou compra de materiais e equipamentos. A OSS não recebe esse recurso, em caso de situação emergencial, por exemplo, de quebra de equipamento, deve ser feita uma solicitação à SES para que possam realizar a troca e posterior repasse, ou a SES pode autorizar que o hospital mesmo possa realizar. Essa é uma desvantagem diante dos 
Artigo original

Hegemonia - Revista Eletrônica de Relações Internacionais do Centro Universitário Unieuro

ISSN: $1809-1261$

UNIEURO, Brasília, número 18, 2016, pp. 260-296.

outros estados, a lei foi feita de uma forma muito rígida e tem essa contradição, pois a proposta era que os processos fossem mais rápidos, mas na verdade não são, pois nós dependemos do estado para obras e investimentos como qualquer outro serviço público".

GC relata em sua fala dificuldades relacionadas ao estabelecimento do orçamento repassado à instituição, porém ao ser questionado diretamente sobre as dificuldades pelas quais passa em sua gestão não dissocia a limitação de um ponto positivo, quando diz que "se por um lado, há limitações relacionadas ao plano orçamentário, por outro a equipe se sente muito mais apropriada do processo, o problema percebido é solucionado na prática com muita rapidez".

Quadro 4. Quadro Síntese sobre dificuldades encontradas no modelo OSS. Brasília, 2013.

\begin{tabular}{|c|c|c|}
\hline \multicolumn{3}{|c|}{ DIFICULDADES ENCONTRADAS NO MODELO OSS } \\
\hline A & Instituição / Gestor \\
\hline Legislação local & Falta recurso de & C \\
restritiva; & investimento; & \\
Semelhanças & Falta de autonomia para & Limitações \\
com a gestão & execução de obras ou & relacionadas ao \\
pública & compra de materiais e & plano \\
tradicional; & equipamentário. \\
& Legislação muito rígida. & \\
\hline
\end{tabular}

Fonte: Elaborado pelo autor.

O modelo de gestão hospitalar por OSS apresenta particularidades em cada um dos estados presentes nesse estudo, o que admite diferenças e dificuldades características de cada lugar. A rigidez ou limitação na legislação local podem vir a dificultar a realização dos 
Artigo original

Hegemonia - Revista Eletrônica de Relações Internacionais do Centro Universitário Unieuro

ISSN: $1809-1261$

UNIEURO, Brasília, número 18, 2016, pp. 260-296.

processos, o que poderá tornar essa modalidade pouco eficiente em longo prazo.

Destaque deve ser dado a semelhança das três instituições quanto à rigidez da legislação, o que demonstra a seriedade do Estado e controle quanto a execução de diversos produtos além do limite orçamentário proposto para tais unidades.

Item 5. Estabelecimento e revisão contratual

A determinação de um contrato de metas, documento que formaliza a relação o estado e a OSS e o repasse de verba da SES para a unidade hospitalar, acontece de um modo geral a partir de negociações entre as duas instituições, onde são ponderadas as necessidades dos serviços que devem ser prestados e os custos que traz essa prestação de serviços.

GA relata que "no estabelecimento do contrato, quem define as necessidades é o contratante, nesse caso o poder público. $O$ estabelecimento dos valores é baseado nos valores de mercado". Sobre a localidade onde está inserido, comenta sobre a novidade de um modelo como esse, dizendo que "a falta de tradição local dificulta a estimativa dos custos, porque o poder público não sabe quanto custa o seu serviço". Porém ressalta que "no cumprimento das metas estabelecidas estamos de um modo geral, indo muito bem. Há algumas discrepâncias, algumas metas cumprimos com folga, outras temos mais dificuldades. O que demonstra uma falta de planejamento no estabelecimento dessas metas, que foram estimadas, baseadas em outras experiências de outros hospitais de mesmas características. Ressalto que o não cumprimento de metas, quantitativas ou qualitativas, se transforma em uma punição pecuniária e podem justificar até o rompimento do contrato". 
Artigo original

Hegemonia - Revista Eletrônica de Relações Internacionais do Centro Universitário Unieuro

ISSN: $1809-1261$

UNIEURO, Brasília, número 18, 2016, pp. 260-296.

Segundo GB, no estado em que IB está inserida "a SES propõe o contrato com metas, que são revistas conforme a realidade do hospital, mas as metas não são difíceis de serem atingidas, pois são estipuladas em modo de negociação entre a SES e a OSS".

De modo mais explicativo GC diz que "a secretaria de saúde é a dona do contrato, você faz o que eles querem. Pois eles é que percebem a rede como um todo, e por isso estabelecem as prioridades e necessidades (o que e quanto ela quer que o hospital ofereça, sejam consultas, procedimentos, cirurgias), nós recebemos essa demanda, e vemos o custo disso. Então há negociação para assentar as metas e a orçamentação".

Quanto às informações sobre o contrato da IA, o GA expõe: "O nosso contrato tem validade máxima de 5 anos, podendo ser atualizado anualmente".

$\mathrm{Na}$ IB, "o contrato tem duração de 5 anos, e a cada ano ele pode ser revisto, podendo ser feito um termo aditivo de repasse financeiro baseado nos custos do serviço" segundo GB.

Segundo GC o contrato da IC "é renovado anualmente, podendo ter readequação de metas de 3 em 3 meses conforme os acontecimentos."

Quadro 5. Quadro Síntese sobre estabelecimento e revisão contratual. Brasília, 2013.

\begin{tabular}{|c|c|c|}
\hline \multicolumn{3}{|c|}{ ESTABELECIMENTO E REVISÃO CONTRATUAL } \\
\hline Instituição / Gestor & B & C \\
\hline A & SES define & SES define \\
Orçamento com base em & necessidades; & necessidades; \\
valores de mercado; & Revisão de metas & OSS verifica \\
Poder público desconhece & conforme & custos; \\
& & \\
\hline
\end{tabular}


Artigo original

Hegemonia - Revista Eletrônica de Relações Internacionais do Centro Universitário Unieuro

ISSN: $1809-1261$

UNIEURO, Brasília, número 18, 2016, pp. 260-296.

\begin{tabular}{|c|c|c|}
\hline $\begin{array}{c}\text { custo dos serviços; } \\
\text { Contrato válido por até } 5 \\
\text { anos; } \\
\text { Atualização anual do } \\
\text { contrato. }\end{array}$ & $\begin{array}{l}\text { realidade. } \\
\text { Contrato válido por } \\
\text { até } 5 \text { anos; } \\
\text { Atualização anual } \\
\text { do contrato. }\end{array}$ & $\begin{array}{l}\text { Contrato renovado } \\
\text { anualmente; } \\
\text { Readequação de } \\
\text { metas } \\
\text { trimestralmente. }\end{array}$ \\
\hline
\end{tabular}

Fonte: Elaborado pelo autor.

As necessidades são estabelecidas pelo Estado, fato de grande importância, afinal é o Estado que tem o papel de gerenciar e adequar à sua necessidade o que vai ser ofertado pela OSS, exercendo assim a sua função de planejar. Tais necessidades são delegadas às OSS que vão deter o poder de execução de acordo com as metas estabelecidas.

Os contratos têm validade estabelecida, porém as SES de cada estado permanecem em contato com as unidades hospitalares para que as metas estejam sempre adequadas ao momento vivenciado pelas unidades, e por isso há possibilidades de ajustes contratuais antes que ele se finde.

Item 6. Relacionamento do hospital de modalidade OSS e órgãos do estado.

GA explica a estrutura formada para compor vínculo entre a SES e a unidade hospitalar: "Existe uma estrutura hierárquica, cada contrato assinado com o governo local por OSS, constitui uma comissão da SES de acompanhamento de contrato, que quando formada é publicada em diário oficial. Temos reuniões regulares com essa comissão. A comissão é o interlocutor de todas as nossas ações com a SES e os órgãos de controle". 
Artigo original

Hegemonia - Revista Eletrônica de Relações Internacionais do Centro Universitário Unieuro

ISSN: $1809-1261$

UNIEURO, Brasília, número 18, 2016, pp. 260-296.

$\mathrm{Na}$ IB "o tribunal de contas não tem relação direta conosco, a solicitação de documentos e as auditorias acontecem através da secretaria, por isso a relação com a SES é bem estreita".

GC conta que "o relacionamento com a SES se dá no dia a dia, e é um bom relacionamento de parceria, nos reunimos de 3 em 3 meses, para analisarmos os indicadores e fazermos as adequações se forem necessárias".

Quadro 6. Quadro Síntese sobre Relacionamento do hospital de modalidade OSS e órgãos do estado. Brasília, 2013.

\begin{tabular}{|c|c|c|}
\hline \multicolumn{3}{|c|}{ RELACIONAMENTO DO HOSPITAL DE MODALIDADE OSS E ÓRGÃOS } \\
DO ESTADO \\
\hline \multicolumn{3}{|c|}{ Instituição / Gestor } \\
\hline A & B & C \\
\hline Comissão de & Principal vínculo: & Principal vínculo: \\
acompanhamento & SES; & SES; \\
contratual (SES); & OSS se reporta a & Reuniões trimestrais \\
Reuniões regulares entre & SES; & com a SES; \\
OSS e comissão; & SES se reporta a & Análise conjunta de \\
Comissão como & tribunais de & readequações para \\
interlocutor com SES e & contas. & necessárias. \\
órgãos de controle. &
\end{tabular}

Fonte: Elaborado pelo autor.

Verifica-se que a SES dos estados é quem acompanha a execução dos contratos, e o faz por meio tanto de comissões quanto em reuniões sistemáticas junto às OSS. Esse "controle" é importante para a transparência da execução e prestação de contas junto aos órgãos de controle.

Item 7. Considerações sobre a legislação local. 
Artigo original

Hegemonia - Revista Eletrônica de Relações Internacionais do Centro Universitário Unieuro

ISSN: $1809-1261$

UNIEURO, Brasília, número 18, 2016, pp. 260-296.

GA considera "a legislação local é restritiva, mas eu creio que estamos em um processo, hoje vivemos uma crise de credibilidade na sociedade, onde toda e qualquer iniciativa mais nova, já nasce com o estigma da suspeição". Para ele "Ao invés de gerenciar resultados, busca-se criar uma série de meios e prerrogativas para evitar e coibir abusos, mas na maioria das vezes não consegue coibir esses abusos, mas impede a execução adequada dos serviços, em nome de um suposto rigor no desenvolvimento da gestão do recurso público, praticamente se impossibilita essa gestão e a torna sempre mais onerosa para a população".

GB demonstra preocupação em sua fala, diz que "se a legislação não for revista, a tendência é que os hospitais gerenciados por OSS no estado tenham, em longo prazo, a dificuldade de investir em infraestrutura e equipamentos que qualquer hospital de administração direta".

Para GC "a legislação deixa algumas brechas de interpretação para os órgãos fiscalizadores, somos fiscalizados pela Secretaria da Fazenda, Secretaria de Saúde, pelo Tribunal de Contas do Estado e às vezes também pelo Tribunal de Contas da União. Alguns entendem que pelo dinheiro ser público ele estaria sujeito às mesmas normativas de qualquer outra instituição da administração direta".

Quadro 7. Quadro Síntese sobre considerações sobre a legislação local. Brasília, 2013.

\begin{tabular}{|c|c|c|}
\hline \multicolumn{3}{|c|}{ CONSIDERAÇÕES SOBRE A LEGISLAÇÃO LOCAL } \\
\hline \multicolumn{3}{|c|}{ Instituição / Gestor } \\
\hline A & B & C \\
\hline $\begin{array}{c}\text { Legislação é restritiva; } \\
\text { Legislação como }\end{array}$ & Legislação & Legislação com \\
rigorosa; & brechas de \\
\hline
\end{tabular}


Artigo original

Hegemonia - Revista Eletrônica de Relações Internacionais do Centro Universitário Unieuro

ISSN: $1809-1261$

UNIEURO, Brasília, número 18, 2016, pp. 260-296.

\begin{tabular}{|c|c|c|}
\hline prerrogativa para evitar & $\begin{array}{c}\text { Sem revisão na } \\
\text { lei, hospitais } \\
\text { tendem a passar }\end{array}$ & $\begin{array}{c}\text { interpretação para os } \\
\text { órgãos fiscalizadores; } \\
\text { Entendimento } \\
\text { errôneo: dinheiro }\end{array}$ \\
Rigor impede execução & pelas mesmas & público sujeito às \\
adequada de serviços; & dificuldades da & mesmas normativas \\
Ônus para a população. & administração & da administração \\
& direta. & direta. \\
\hline
\end{tabular}

Fonte: Elaborado pelo autor.

Todos os entrevistados foram categóricos quanto ao rigor legislativo. E que por vezes tem tornado difícil a execução das atividades que se propõe a instituição.

Merece destaque de que tal rigor é importante, pois demostra controle das ações por parte do Estado. Por outro lado, deve-se considerar que certa ou alguma autonomia deve ser dada às OSS para que possam exercer um papel às vezes mais efetivo do que 0 atual. Exemplo disso pode ser verificado na fala da GB.

Em reforço ao rigor que a lei deve ter, Silva Neto (2002) afirma que ter que o controle sobre as organizações sociais fundamenta-se no poder-dever que tem a Administração de verificar se a utilização dos bens e valores públicos estão sendo feitos, conforme o seriam, se feitos pelo próprio Estado, até porque as atividades contempladas no contrato de gestão devem guiar-se por princípios de direito público.

Item 8. Considerações sobre a fiscalização.

GA levanta o seu ponto de vista, dizendo que "uma questão importante hoje no Brasil em todos os setores da gestão pública, é que toda avaliação é fundamentada em processos, e não em 
Artigo original

Hegemonia - Revista Eletrônica de Relações Internacionais do Centro Universitário Unieuro

ISSN: $1809-1261$

UNIEURO, Brasília, número 18, 2016, pp. 260-296.

resultados. Os órgãos de controle avaliam processos, o que importa é cumprir o ritual rigorosamente".

No estado onde IB está inserida "o tribunal de contas tem sido bastante resistente e rígido no que diz respeito às OSS, por ser recente essa modalidade, e pela recente legislação". Porém, GB pondera: "mas o tempo tem feito os ajustes necessários e conseguimos realizar tudo conforme a lei e passando por essas auditorias".

GC acredita que o processo de fiscalização traz melhorias, e diz: "quanto mais somos auditados, mais aprimoramos os mecanismos de controle e consequentemente mais transparente se torna os processos. O grande desafio é ter toda a transparência solicitada e ainda assim manter a agilidade na execução dos processos".

Quadro 8. Quadro Síntese sobre considerações sobre a fiscalização.

Brasília, 2013.

\begin{tabular}{|c|c|c|}
\hline \multicolumn{3}{|c|}{ CONSIDERAÇÕES SOBRE A FISCALIZAÇÃO } \\
\hline \multicolumn{3}{|c|}{ Instituição / Gestor } \\
\hline A & B & C \\
\hline Avaliações & Tribunais de & Auditorias aprimoram \\
fundamentadas em & contas rígidos; & controle e aumentam \\
processos; & Com ajustes, & transparência de \\
Resultados menos & realizações & processos; \\
significativos nas & estão dentro da & Desafio: transparência com \\
avaliações. & lei. & agilidade. \\
\hline
\end{tabular}

Fonte: Elaborado pelo autor.

Deve-se considerar que a atuação do Estado, como fiscalizadora do processo junto às OSS é fundamental desde que transparente para o processo ocorrer de forma adequada. O aprimoramento e 
Artigo original

Hegemonia - Revista Eletrônica de Relações Internacionais do Centro Universitário Unieuro

ISSN: $1809-1261$

UNIEURO, Brasília, número 18, 2016, pp. 260-296.

crescimento institucional dessas OSS pode se dar após muitas das auditorias/fiscalizações. Esse é um processo contínuo e necessário.

A fala de GA é refletida no texto de Ibanez e Vecina Neto (2007), órgãos como os Tribunais de Contas, são voltados para o controle de meios e não de resultados, eles ainda dizem que o Estado deve melhorar a sua capacidade para controlar a execução dos recursos colocados à disposição das organizações, tanto do ponto de vista da execução quanto do alcance dos resultados.

Item 9. Oposição ao modelo OSS.

Sobre as polêmicas que geram oposições ao modelo OSS, GA explica: "eu entendo que as OSS não são uma panaceia universal, não entendo que deva ser adotado como modelo único, é preciso testar outros modelos". Ele pondera sobre as alternativas para uma gestão mais qualificada diante da gestão tradicional: "Eu entendo que o maior problema da saúde hoje seja a gestão e não a falta de dinheiro, porque se colocarmos mais dinheiro, com uma má gestão, vai ser mais dinheiro indo pro ralo".

GB destaca o principal acontecimento decorrente do movimento oposicionista às OSS: "Como havia uma grande resistência às OSS, a lei foi construída com muita rigidez para que fosse facilitada em sua aprovação. A legislação é limitante".

GC acredita que os componentes dos órgãos públicos de controle possam formar oposição, ele diz: "Os funcionários públicos, que compõe esses órgãos podem se sentir ofendidos, de certa forma, quando dizemos que o modelo OSS é mais eficiente. Mas se esquecem de que o Estado não produz nada, nem na esfera federal, estadual ou municipal, o Estado arrecada, faz a distribuição e a fiscalização e para isso, geralmente ele é bom. Quando chega a hora 
Artigo original

Hegemonia - Revista Eletrônica de Relações Internacionais do Centro Universitário Unieuro

ISSN: $1809-1261$

UNIEURO, Brasília, número 18, 2016, pp. 260-296.

do Estado se colocar como prestador de serviços, há problemas, como na saúde e na educação que são setores alvos de muitas reclamações". Ele destaca a falha da administração pública direta: "a morosidade da administração pública tem consequência muito grande para o usuário".

GC conclui esperançoso sobre as oposições dizendo: "Eu acho que essa oposição já foi maior. Os opositores iniciais hoje já podem ver os resultados, as fiscalizações feitas regularmente, ano após ano é mostrada a transparência do processo e a eficiência dele a resistência vai acabando".

Quadro 9. Quadro Síntese sobre oposição ao modelo OSS. Brasília, 2013.

\begin{tabular}{|c|c|c|}
\hline \multicolumn{3}{|c|}{ OPOSIÇÃO AO MODELO OSS } \\
\hline \multicolumn{3}{|c|}{ Instituição / Gestor } \\
\hline A & B & $C$ \\
\hline & & Possível ofensa a funcionários \\
\hline OSS não são & Grande & públicos; \\
\hline panaceias & resistência das & Não se leva em consideração \\
\hline universais; & categorias & que o Estado que arrecada, \\
\hline Devem testar & profissionais; & distribui e fiscaliza bem; \\
\hline outros & Lei construída & Estado falha ao prestar de \\
\hline modelos; & com rigidez para & serviços; \\
\hline Problema da & aprovação; & Opositores iniciais hoje veem \\
\hline saúde é a & Legislação se & resultados, fiscalizações \\
\hline gestão. & tornou limitante. & $\begin{array}{c}\text { mostram transparência e } \\
\text { eficiência do modelo. }\end{array}$ \\
\hline
\end{tabular}

Fonte: Elaborado pelo autor.

Há que se ressaltar que a administração pública no que se refere às modalidade de prestação de serviços, cresceu muito nas 
Artigo original

Hegemonia - Revista Eletrônica de Relações Internacionais do Centro Universitário Unieuro

ISSN: $1809-1261$

UNIEURO, Brasília, número 18, 2016, pp. 260-296.

últimas décadas, a exemplo das OSS e das parcerias público privadas. E as oposições quanto a essas modalidades vão ocorrer, pois numa sociedade democrática se espera oposições, aceites e críticas. É importante destacar que essas críticas e oposições permitem a consolidação do processo de gestão dessas modalidades, como forma de crescimento e desenvolvimento do aparato administrativo público.

Item 10. Opinião pessoal sobre o modelo OSS.

GA expões que, para ele, "o modelo de gestão OSS não necessariamente está associado à excelência da assistência, não é predefinição eu entendo que por conta do emaranhado jurídico e das dificuldades da administração pública, o modelo de OSS é uma saída para as dificuldades do sistema. Do ponto de vista do poder público, apresenta grande vantagem com relação a se dedicar mais ao acompanhamento e à monitoração da prestação desses serviços. A excelência vai depender de como a gestão pública orienta e trabalha sobre as OSS".

GB entende que "as OSS podem ser uma ferramenta que ajuda o estado a cumprir o seu dever de prover a saúde, afinal de contas é o Estado que mantém a unidade, foi ele que construiu a unidade, e o Estado cobra da OSS através das metas". Ele ainda afirma que diante das outras formas de gestão tradicionais, as OSS "são muito mais cobrados que a administração direta que não possui metas, se não cumprimos somos punidos financeiramente no repasse de verba".

GC afirma que "o Estado tem o dever, mas não de prover diretamente. Acho que ele tem que ser eficiente, evitando os desvios de recursos, e otimizando esses recursos. Acho que cabe ao Estado a fiscalização e a ordenação do que ele quer, mapear, planejar e dar a 
Artigo original

Hegemonia - Revista Eletrônica de Relações Internacionais do Centro Universitário Unieuro

ISSN: $1809-1261$

UNIEURO, Brasília, número 18, 2016, pp. 260-296.

execução para quem tem agilidade para fazer". GC é incisivo ao dizer que "o Estado não constrói estradas, não tem engenheiros civis construindo por aí, para isso contrata. Por que em áreas tão essenciais, como a saúde, ele tem que ser o prestador?", o questionamento leva a dizer que "o modelo OSS desde que a legislação seja cumprida, vem aprimorar o SUS, se o Estado quer o sistema único universalizado, deve mapear e dar às OSS o direito à execução, acompanhando e fiscalizando os indicadores e metas". E finaliza dizendo: "Acho que esse é um modelo que veio pra ficar em todas as áreas, você tem a eficiência do setor privado, fazendo a gestão do dinheiro público".

Quadro 10. Quadro Síntese sobre opinião pessoal sobre o modelo OSS. Brasília, 2013.

\begin{tabular}{|c|c|c|}
\hline \multicolumn{3}{|c|}{ OPINIÃO PESSOAL SOBRE O MODELO OSS } \\
\hline \multicolumn{3}{|c|}{ Instituição / Gestor } \\
\hline$A$ & $B$ & $\mathrm{C}$ \\
\hline Modelo OSS não é & Modelo OSS como & O Estado tem o \\
\hline predefinição de & ferramenta que & dever de prover, não \\
\hline excelência assistencial; & ajuda o estado a & necessariamente \\
\hline OSS como alternativa & cumprir o seu & diretamente; \\
\hline para as dificuldades do & dever de prover a & Modelo OSS, \\
\hline sistema; & Saúde; & cumprindo a lei, \\
\hline Poder público realiza & Estado controla & aprimora o SUS; \\
\hline melhor & mais OSS do que & Estado deve dar às \\
\hline acompanhamento e & unidades da & OSS o direito à \\
\hline monitoramento da & gestão pública & execução; \\
\hline prestação desses & direta. & Eficiência do setor \\
\hline serviços; & & privado, fazendo a \\
\hline $\begin{array}{l}\text { A excelência depende de } \\
\text { como a gestão pública }\end{array}$ & & $\begin{array}{l}\text { gestão do dinheiro } \\
\text { público }\end{array}$ \\
\hline
\end{tabular}


Artigo original

Hegemonia - Revista Eletrônica de Relações Internacionais do Centro Universitário Unieuro

ISSN: $1809-1261$

UNIEURO, Brasília, número 18, 2016, pp. 260-296.

orienta e trabalha sobre

as OSS.

Fonte: Elaborado pelo autor.

O destaque feito pelos gestores das unidades mostra que há uma percepção clara do papel exercido pelo Estado e da importância de novas modalidades de gestão. Todos esses gestores já participaram diretamente de experiências junto a administração direta, ou seja, conhecem o outro lado da gestão pública.

Experiências exitosas devem ser registradas a fim de demonstrar que o aparelhamento atual do Estado permite inovações. E tais inovações vão ao encontro do princípio constitucional, que no caso da saúde é claro e incisivo: "A saúde é direito de todos e dever do Estado" (BRASIL, 1988).

Considerações Finais

A gestão de unidades hospitalares por meio de organizações sociais de saúde é uma modalidade nova, apesar de ter legislação federal há cerca de quinze anos. Alguns estados começaram a adotar esse tipo de modelo há pouco tempo. Por essa razão o modelo de organizações sociais de saúde pode ser pouco compreendido, por muitas vezes, ser confundido com outras formas de parcerias públicoprivadas.

A forma de contratualização existente entre o Estado e uma instituição qualificada como organização social de saúde, pode se assemelhar muito a uma gestão pública direta se o contrato estabelecido entre as partes não for eficiente de modo que garanta o gerenciamento dos recursos com maior qualidade e menor custo para uma assistência eficiente. 
Artigo original

Hegemonia - Revista Eletrônica de Relações Internacionais do Centro Universitário Unieuro

ISSN: $1809-1261$

UNIEURO, Brasília, número 18, 2016, pp. 260-296.

É importante ressaltar que o envolvimento do Estado é fundamental para o sucesso desse modelo, há uma via de mão dupla onde cada uma das partes deve exercer sua função com presteza. À unidade hospitalar gerida por OSS cabe a execução adequada dos processos e o compromisso de publicização das atividades que realiza; e ao Estado, e contratante, cabe a fiscalização e o controle sobre as metas que estipula como necessidades.

As unidades aqui estudadas apresentam processos distintos em sua atual execução e também em sua fundação inicial. As normativas, legislações e práticas de cada estado da federação também compreendem particularidades que tornam o mesmo modelo bastante distinto em cada lugar, seja pela falta de tradição ou pelos rigores advindos das oposições. Apesar disso as constatações sobre tal modelo do ponto de vista dos gestores entrevistados trazem semelhanças importantes e consideráveis.

Cabe ao serviço público realizar monitoramento e avaliação dos processos e dos serviços prestados pelas unidades hospitalares, pois o modelo por si só não garante sucesso, mas o adequado acompanhamento, associado à boa gestão pode fazer desse modelo um caminho a excelência do SUS.

Da mesma forma, a legislação deve ser acompanhada, para que esteja sempre atualizada, em conformidade com as propostas do modelo. Devendo ser uma aliada a realização das atividades das unidades hospitalares, e não fatores de impedimento de crescimento dessas organizações. Assim evitando que as atuais falhas da administração direta cheguem a preencher, também, as novas modalidades de gestão.

Ressalto que poucos estudos são encontrados, e por isso são necessárias novas análises de experiências nessa modalidade de gestão em unidades hospitalares. É fundamental que a academia se 
Artigo original

Hegemonia - Revista Eletrônica de Relações Internacionais do Centro Universitário Unieuro

ISSN: $1809-1261$

UNIEURO, Brasília, número 18, 2016, pp. 260-296.

aproprie desses registros e produza literatura que possa contribuir para os novos rumos da gestão em saúde.

\section{REFERÊNCIAS BIBLIOGRÁFICAS}

ABRUCIO, F. L.; SANO, H. Promessas e resultados da nova gestão pública no Brasil: o caso das organizações sociais de saúde em São Paulo. Revista de Administração de Empresas, Brasil, v.48, n.3, p.64-80, 2008.

ANDRADE, E. P. de. Gestão de terceiros. In: IBAÑEZ, N. et al (orgs) Política e Gestão Pública em Saúde. São Paulo: Hucitec Editora: Cealag, 2011.

BARBOSA, N. B.; ELIAS, P. E. M. As organizações sociais de saúde como forma de gestão público/privado. Ciênc. saúde coletiva, Rio de Janeiro, v. 15, n. 5, ago. 2010. Disponível em <http://www.scielo.br/scielo.php?script=sci_arttext\&pid=S1413$81232010000500023 \&$ lng =pt\&nrm=iso >. Acessos em 15 jan. 2013. BRASIL. Conselho Nacional de Secretários de Saúde. Sistema Único de Saúde / Conselho Nacional de Secretários de Saúde. - Brasília: CONASS, 2011. Cap 1. (Coleção Progestores - Para entender a gestão do SUS, 8).

BRASIL. Constituição da República Federativa do Brasil, de 05 de outubro de 1988. Institui a Constituição da República Federativa do Brasil. Brasília, 1988.

BRASIL. Lei no 9637, de 15 de maio de 1998. Dispõe sobre a qualificação de entidades como organizações sociais, a criação do Programa Nacional de Publicização, a extinção dos órgãos e entidades que menciona e a absorção de suas atividades por organizações sociais, e dá outras providências. 
Artigo original

Hegemonia - Revista Eletrônica de Relações Internacionais do Centro Universitário Unieuro

ISSN: $1809-1261$

UNIEURO, Brasília, número 18, 2016, pp. 260-296.

BRASIL. Ministério da Administração Federal e Reforma do Estado / Secretaria de Reforma do Estado. Organizações sociais. Brasília, 1997. (Cadernos MARE da Reforma do Estado. v.2).

BRASIL. Norma Operacional Básica do SUS - NOB-SUS 01/96. In:

Diário Oficial da União. Brasília. Novembro de 1996.

COSTA, I. M. C.; JUNIOR, N. C.; NASCIMENTO, V. B. Relação entre público e privado na atenção primária à saúde: considerações preliminares. Saúde e Sociedade, São Paulo, v.20, n.4, p.971-979, 2011.

DISTRITO FEDERAL. Lei no 2.415, de 6 de julho de 1999. Dispõe sobre a qualificação de entidades como organizações sociais no âmbito do Distrito Federal.

DISTRITO FEDERAL. Lei no 2.523, de 13 de janeiro de 2000. Altera a Lei $n^{\circ}$ 2.415, de 6 de julho de 1999, que trata da qualificação de entidades como organizações sociais no âmbito do Distrito Federal.

IBANEZ, N.; VECINA NETO, G. Modelos de gestão e o SUS. Ciênc. saúde coletiva, Rio de Janeiro, 2007. Disponível em <http://www.scielo.br/scielo.php?script=sci_arttext\&pid=S1413$81232007000700006 \&$ lng =pt\&nrm=iso>. Acessos em 25 fev. 2013. PERNAMBUCO. Lei no 11.743 de 20 de janeiro de 2000. Sistematiza a prestação de serviços públicos não exclusivos, dispõe sobre a qualificação de Organizações Sociais e da Sociedade Civil de interesse público e o fomento às atividades sociais, e dá outras providências.

Presidência da República, CÂMARA DA REFORMA DO ESTADO. Plano Diretor da Reforma do Aparelho do Estado. Brasília, 1995.

SANTOS, L. Administração pública e a gestão da saúde. In: SANTOS, N. R.; AMARANTE, P. D. de C.(orgs) Gestão Pública e Relação Público Privado na Saúde. Rio de Janeiro: Cebes, 2010. 


\section{Artigo original}

Hegemonia - Revista Eletrônica de Relações Internacionais do Centro Universitário Unieuro

ISSN: $1809-1261$

UNIEURO, Brasília, número 18, 2016, pp. 260-296.

SÃO PAULO. Lei complementar no 846, de 4 de junho de 1998.

Dispõe sobre a qualificação de entidades como organizações sociais e dá outras providências. 